\title{
Considerações sobre a Dialética do Abstrato e do Concreto na Circulação Simples de $O$ Capital
}

\section{Hélio Ázara de Oliveira ${ }^{1}$}

Resumo: Marx inicia a exposição categorial de sua principal obra pela circulação simples, isto é, pelo abstrato capitalista. Esta "opção" não é, sem dúvida, acidental. Ela é fruto e resultado de uma adesão metodológica clara. Procuramos neste artigo analisar de que modo a dialética do abstrato e do concreto estrutura a exposição que abre $O$ Capital, e, em um segundo momento, procuramos destacar como esta dialética se reporta a uma relação ainda mais ampla, aquela que existe entre aparência e essência. Com isso buscamos ressaltar a herança filosófica da qual parte Marx ao fazer a seu diagnóstico da sociedade moderna.

Palavras-chave: O Capital, Circulação-Simples, Concreto, Abstrato.

Abstract: Marx starts the categorical exhibition of his main work through simple circulation, that is, through the capitalist abstract. It is, certainly, not an accidental "choice". It is the result of a clear methodological adherence. We seek to analyze in this paper how the dialectic of the abstract and the concrete structures the explanation that opens The Capital, and, in a second moment, we attempt to emphasize how this dialectic refers to an even wider relation between appearance and essence. Our aim is to examine the philosophical heritage which is Marx`s starting point in regard to his diagnose of the modern society

Keywords: The Capital, Simple Circulation, Concrete, Abstract.

${ }^{1}$ Doutorando pelo programa de pós-graduação em filosofia - IFCH/UNICAMP. Pesquisador do Centro de Estudos em Filosofia Moderna e Contemporânea CEMODECOM. 
Marx, na Introdução ao Método da Economia Política, testemunha a dificuldade para se decidir por onde começar a exposição sobre a crítica da economia política. É ainda mais difícil começar a exposição dos resultados de uma investigação que visa reconstruir a constituição sistemática do capital a partir de determinações mais simples, abstratas e aparentes. Sobretudo para uma obra que, não obstante se constituir de uma crítica, pretende proceder na exposição sem exterioridade ao seu objeto, antes pretende descobrir suas leis essenciais, sua gênese e devir, e os caminhos de sua superação. Certamente poderia "parecer correto começar pelo real e pelo concreto, pela pressuposição efetivamente real", afinal, não se trata de materialismo? Marx, porém, nos revela em suas breves reflexões metodológicas estar informado e convencido de que começando pelo concreto "haveria não mais que uma representação caótica do todo", o que revela o engano e a falsidade deste caminho tantas vezes trilhado. Poderia ainda parecer mais correto começar pelos "primeiros inícios" do objeto analisado, ou seja, fazer sua história de surgimento e constituição, alinhar as categorias na ordem de seu aparecimento na história, da primeira até a última. Isto sim, se poderia pensar, é materialismo histórico! Talvez, ao menos se o próprio Marx não tivesse dito que "seria, além de impossível, falso, ordenar as categorias econômicas na sucessão em que foram historicamente determinantes" (MARX, 1996, p. 9). Ainda conforme esta Introdução, que o próprio autor não publicou para não perturbar com antecipações os resultados da pesquisa, o método empregado em $O$ Capital é o oposto direto dos dois modelos acima. Uma vez que se trata de crítica da economia política, o melhor caminho é partir dos melhores representantes desta ciência, dos sistemas mais elevados, iniciando "pelos elementos mais simples", como o trabalho e o valor de troca, e elevar-se progressivamente até as determinações mais complexas e concretas, como o capital, o Estado, o mercado mundial. Para Marx não resta dúvida de que "o último caminho é o método cientificamente correto. $\mathrm{O}$ concreto é concreto por ser uma concentração de muitas determinações, logo, unidade do múltiplo" (Idem). Marx, portanto, parte 
das determinações abstratas e são essas que nos conduzem pelo caminho da exposição ao concreto no plano do pensamento.

Ao iniciar sua obra pela circulação simples, Marx não nos está apresentado nem o "concreto capitalista", nem sua "história de surgimento", e ainda menos sua "pré-história". O que nos apresenta é o mundo capitalista em uma versão abstrata. Entenda-se aqui por abstrato: a representação de algo, no caso um modo de produção, a que todas as determinações necessárias à sua compreensão não foram ainda somadas. Este abstrato é, não obstante, o capitalismo como este aparece à consciência imediata que temos dos processos sociais nos quais nos envolvemos. Esta abstração, entendida como consciência dos agentes econômicos, é abstração real e não mera ilusão. É, para utilizar uma metáfora que nos acompanhará neste trabalho, o capitalismo como este aparece em sua epiderme. A circulação simples na acepção em que a tomaremos neste trabalho reproduz o "movimento efetivo" da consciência dos agentes ao mesmo tempo em que encaminha esta consciência para a crítica de sua superficialidade e de sua verdade apenas aparente. Ou seja, a Seção I de O Capital tematiza, conjuntamente com a descrição econômica, a consciência dos agentes dos processos mercantis. A crítica de sua parcialidade descritiva, embora presente como pressuposiçãa desde o início, será atualizada finalmente a partir da Seção VII do livro primeiro de $O$ Capital. Este caminho, como totalidade (apenas pressuposta neste trabalho), mostra que o racional e o concreto,

Não são de acesso imediato a qualquer tipo de intuição intelectual ou experiência direta, que intuiria ou tomaria o objeto no seu ser dado imediato, mas que eles são o resultado de um movimento de pensamento, do que Hegel chama de 'trabalho do conceito', que expõe progressivamente, a partir das determinações mais simples e abstratas do conteúdo, suas determinações cada vez mais ricas, complexas e intensas, até o ponto de sua unidade, que não é só unidade formal, mas unidade sintética de múltiplas determinações. ${ }^{2}$ (MÜLLER, 1982, p. 22-23)

${ }^{2}$ Como procura demonstrar Müller, no que diz respeito a esta parte do "método de exposição" o que vale para Hegel vale igualmente para Marx. 
No presente trabalho acompanharemos Marx na etapa inicial do método de exposição, a saber, a explicitação das determinações mais "simples e abstratas do conteúdo", que em sua totalidade constituem a crítica da economia política e do mundo do capital. Na epiderme do mundo capitalista, na qual nos movemos como agentes dos processos de troca, reina unicamente identidade entre os agentes, a liberdade, a igualdade dos contratantes e o interesse próprio de cada agente que, nessa esfera, é guiado providencialmente para o bem de todos. Estas são as "determinações simples e abstratas" que aparecem como reais, como consciência real da sociabilidade capitalista.

Marx, em Para a Crítica da Economia Política, indica que o feitiço exercido pelas mercadorias deve-se à "rotina da vida cotidiana que faz parecer trivial e óbvio o fato de uma relação social de produção assumir a forma de um objeto" (MARX, 1999, p. 63). Tal mistificação decorreria do fato de que na "rotina da vida cotidiana" não são percebidas, devido ao fato de estarem encobertas por relações reificadas, as relações de produção mais elevadas, e o conflito entre a força de trabalho e as relações de produção. Este "hábito" se torna uma "crosta de preconceitos", que vela o significado mais profundo da própria ação e banaliza a inversão entre o tratamento de homens e coisas no mundo das mercadorias. O trabalho crítico consistiria em revelar as relações de produção subjacentes e, assim, trazer à luz a sua simplicidade apenas aparente e as ilusões adquiridas pela rotina da vida. Diante da crítica caem os ídolos da simplicidade e da identidade entre aparência e essência do modo de produção capitalista. Nosso estudo tem especial interesse por este aspecto do procedimento crítico, a saber, pela denúncia (por meio do contraste) da inverdade das aparências que formam o "mundo das mercadorias" e que encobrem os processos reais de exploração. É este elemento de crítica da percepção imediata que os homens têm de sua própria criação social que alimenta nossa pesquisa ${ }^{3}$.

${ }^{3}$ Como aponta Müller em seu artigo acima citado: "o verdadeiro concreto da realidade capitalista não é dado pela experiência direta da circulação de mercadorias e pelo movimento dos preços, isto é, pelas categorias da circulação, mas é o resultado de um processo de pensamento que reconstrói a constituição sistemática do capital a partir das determinações mais simples, abstratas e aparentes da produção capitalista [...] para chegar às mais ricas, concretas e essenciais" (MÜLLER, 1982, p.23).

32 Considerações sobre a Dialética do Abstrato e do Concreto... 


\section{Sobre Abstrato e Concreto}

Noções como abstrato e concreto, não obstante seu uso corrente, carregam inúmeras dificuldades e são objeto de acalorados debates desde o século XVIII. Em certos textos de Hegel e mesmo de Marx são apenas inteligíveis na sua plenitude no contexto em que ocorrem. Há entre nós, contudo, certa tendência lingüística para entender o abstrato negativamente e associado àquilo que não encontra sentido em si mesmo, aquilo que é insuficiente, dependente, sem vida. Há nesta visão corrente uma prioridade do concreto que é diferente daquela que podemos notar em Marx. $\mathrm{O}$ autor de $\mathrm{O}$ capital não trata concreto e abstrato em termos de maior ou menor importância, nem muito menos com qualquer resquício de conotações ontológicas.

Não se trata de mensurar concreção e abstração e sim de entender o movimento conceitual que nos leva do abstrato ao concreto, movimento este que se torna impossível se abandonarmos de imediato o abstrato para nos lançarmos no concreto, como se assim pudéssemos encontrar "a verdade". Em passagem já citada de O Método da Economia Política, Marx mostra como se enganam os economistas por pensarem que se deve partir do "concreto". Como diz Marx, parece correto, ao considerar a economia política, começar pelo real, pela pressuposição efetivamente real. No caso da economia, parece seguir o caminho do "concreto" quem inicia a pesquisa pela população. Esta aparência se mostra falsa tão logo submetida a uma análise mais precisa. O concreto, como síntese (Zusammenfassung) de muitas determinações, aparece ao pensamento como concentração de determinações, como posterioridade, quando na efetividade real é o ponto de partida.

No método de exposição utilizado por Marx as determinações abstratas conduzem (führen) ao concreto, não como gênese do concreto, mas apenas como caminho de seu conhecimento pelo pensamento. Assim, na análise teórica da circulação simples, como em todo momento teórico, o sujeito, a sociedade (das Subjekt, die Gesellschaft) está sempre presente como pressuposição. 
Na superfície da sociedade do capital, os homens são considerados abstratamente como livres contratantes individuais de um processo que ainda não se reproduz e ainda não se repõe com aquela circularidade auto-referenciada que causará a sua alteração na teoria da reprodução. Contudo, pensamos que a consciência dos agentes não se altera pela posição da reprodução, mas permanece idêntica àquela da circulação simples, não sendo alterada pela teoria, mas apenas pela luta política, não tematizada plenamente ainda na seção que abre $O$ Capital.

A circulação simples, como epiderme do mundo burguês, é a forma como aparecem aos agentes suas relações sociais e de produção como mediadas pela liberdade, pela igualdade e pelo contrato, é uma abstração. Esta "consciência" não anula e nem tampouco corresponde à efetividade do processo subjacente; ao contrário, garante-o e permite pacificamente a sua reprodução ${ }^{4}$. É também neste sentido que a crítica é "crítica dos modos do aparecer". É prudente lembrar que a solução da oposição entre essência e aparência, concreto e abstrato, identidade e luta de classes, não está, em Marx, na teoria. Antes, aponta para fora do campo do pensamento, para a resolução como processo histórico.

Sobre a questão da abstração, lembra-nos Giannotti que em $O$ Capital o abstrato não se entende no sentido de um modelo matemático, isto é, não é uma abstração vazia que possa ser preenchida por um objeto qualquer. E diz a título de exemplo: "A definição de valor não enuncia uma das possíveis formas de encarar a questão, mas a própria natureza da substância social em referência aos seus múltiplos modos de aparecer" (GIANNOTTI, 1960, pp. 66-67). Assim compreendido, o abstrato tem tanto o sentido da generalidade abrangente de todos os casos, como aquele de uma "tendência" para o concreto. Aqui se deve entender o abstrato como aquela "determinação atual" à qual as demais

\footnotetext{
${ }^{4}$ Como pensa Ruy Fausto, a aparência do sistema é de não-violência, tendo o processo como um todo a característica de parecer pacífico. Na superfície, a "violência" contra o sistema é ainda violência. Com a posição da teoria da reprodução, o que antes passava por não-violência, se mostra como violência e exploração. A partir disto, a "violência" contra o sistema se mostra não-violência. Estes são alguns resultados da interversão. (ver FAUSTO, 1983, p. 89ss).
}

34 Considerações sobre a Dialética do Abstrato e do Concreto... 
determinações (igualmente abstratas) não foram ainda somadas. $\mathrm{O}$ abstrato carrega o sentido de provisoriedade, ou melhor, "incompletude". Lembra ainda Giannotti que, nesta acepção, a tarefa crítica de "desmascaramento das aparências" não tem apenas o sentido da redução do fenômeno à sua forma mais simples, mas sim de sua inserção no esquema que lhe dá sentido.

Em nosso problema, tratar-se-ia de inserir a circulação simples na totalidade da produção e das significações capitalistas, o que significa tanto um tratamento das relações de produção subjacentes e escondidas sob o véu místico formado pela circulação simples, como de relacionar a ilusão na aparência do mundo capitalista com as ilusões a ela simétricas, como o fetiche do capital. Visto deste ângulo, nosso trabalho, como nosso objeto, permanece em abstrato.

Cabe ressaltar antes de tudo no problema da abstração a sua ligação com o método, ou seja, com a dialética, entendida por Marx antes de tudo como método de exposição. O que dissemos neste item torna-se concreto tão logo seja integrado na questão do modo/método de exposição, pois aí seu tratamento perde a aparência de mera formalidade, adquire a forma do movimento dos conceitos. Vemos então que abstrato adquire sentido em relação não apenas ao concreto puro e simples (pois não se trata da empiria vulgar) mas em relação ao movimento de "concreção categorial". Como ressalta Grespan, "apesar de dialeticamente a exposição ter uma forma recursivo-progressiva, com o que vem depois sendo pressuposto do que vem antes, tanto quanto este é daquele, há um predomínio das formas mais ricas e complexas, nas quais as mais abstratas e iniciais não são eliminadas, mas redefinidas em seu papel" (GRESPAN, 2002, p. 44).

Neste mesmo sentido, comentando a relação entre Hegel e o marxismo, Colletti afirma que "na Alfhebung (Suspensão/supressão $0^{5}$ ) do

\footnotetext{
${ }^{5}$ Adotamos aqui a sugestão de Marcos Müller em sua tradução da Filosofia do Direito para a tradução de Aufhebung por Suspensão/supressão de acordo com o contexto. Não reproduziremos aqui sua longa "demonstração" dos motivos que o levam a tal opção, mas apenas indicamos que sua proposta de tradução convence da manutenção dos sentidos principais do termo em Hegel, como é sabido elevar, suprimir, guardar. Para um tratamento completo dos detalhes de tradução ver a tradução de Müller à Introdução à Filosofia do Direito, Campinas, IFCH-Unicamp, nota 25, p. 87.
} 
finito [pensamos o movimento da circulação simples] pelo infinito [o movimento do capital] a essência do finito é conservada, donde a possibilidade de se fazer o caminho inverso, de tornar do infinito ao finito, do abstrato ao concreto, da essência ao fenômeno" (COLLETTI, 1969, p. 26). Assim o percurso da concreção categorial não anula a verdade das categorias iniciais, ao menos não no seu todo.

A apresentação dialética é passagem da aparência à essência, mas a aparência permanece como aparência. Nosso estudo limita-se ao plano da aparência, ao plano da epiderme de um organismo mais complexo e que carrega outras contradições que, embora "neguem" as categorias por nós analisadas, de forma alguma faz delas pontos de partida provisórios. Ao contrário, as aparências se mostram necessárias para o funcionamento essencial do sistema como um todo ${ }^{6}$.

\section{Abstração e Epiderme}

Caso pudéssemos utilizar uma metáfora, diríamos que a obra de Marx apresenta-nos a "anatomia da sociedade burguesa", suas múltiplas partes bem como a articulação necessária das partes entre si e de cada uma delas com o todo do organismo capitalista. Cabe-nos aqui unicamente apresentar uma breve reflexão sobre a primeira "camada de sentido" deste corpo, sua epiderme. A circulação simples, como

6 "As determinações já da circulação simples não são simplesmente anuladas pelas da produção capitalista, mas também não são mantidas como se acrescentassem algo fundamental, isto é, que lhes dá um novo fundamento. É superado justamente o conteúdo da circulação simples, o objetivo de vender para comprar valores-de-uso, produtos que satisfaçam necessidades de consumo. Mas a circulação simples existe dentro da capitalista, quando o que circula são simples mercadorias e dinheiro, e não capitalmercadoria e capital-dinheiro; quando não há investimento, mas simples compra de bens de consumo pelos assalariados ou pelos capitalistas que também usam assim parte da mais-valia. Não é que a circulação simples seja mera hipótese irrealista, portanto mero pressuposto lógico para desenvolver o conceito de capital; ela existe, embora de modo subordinado à circulação capitalista. Com sua transformação em momento de um processo maior, é dado a ela agora o papel de executar fases do movimento mais amplo. Não é um erro, então, constatar sua existência, mas sim constatar só sua existência, reduzindo os objetivos do capital a apenas atender a necessidades sociais de consumo" (GRESPAN, 2002, p.45). 
abstração real do mundo capitalista, não é apenas uma determinação exterior e superficial desta formação econômica, mas uma determinação orgânica e contraditoriamente essencial ao seu funcionamento como organismo. Não é aparência que desvanece, mas "camada de sentido" que protege o organismo pelo feitiço da mercadoria. O funcionamento do corpo capitalista não pode prescindir da aparência harmônica da liberdade, da igualdade e da reciprocidade. Sem esta camada a essência do mundo capitalista ficaria exposta e teria dificuldades para seu movimento automático, ao menos teria dificuldades em alcançar os objetivos de sua reposição quanto ao capital variável. O movimentovalor apareceria de início como contradição entre forças produtivas e relações de produção. A metáfora, um acréscimo àquelas utilizadas pelo próprio Marx, serve para que nos lembremos da ligação indissolúvel entre essência e aparência no mundo capitalista. Ambas se nutrem e protegem, ambas são fundamentais para que o movimento-valor se efetive. A circulação simples é por onde se inicia a exposição, que certamente desce até os intestinos do mundo burguês, e demonstra a parcialidade da epiderme harmônica, mesmo que isto não anule seu feitiço sobre os agentes. Essa metáfora alarga o sentido da permanência do feitiço e talvez sirva apenas como expediente para contrabalançar o sentido corrente de aparência.

Insistimos na metáfora por reconhecer a influência de leituras que privilegiam meramente "o momento do entendimento" ou mesmo do que podemos grosso modo qualificar de "materialismo vulgar", cuja concepção de experiência e aparência não estão à altura do refinamento que tais conceitos recebem no texto de Marx. No contexto alemão anterior a Marx estes conceitos são ocasião de acalorado debate filosófico. Desde a publicação da Crítica da Razão Pura, Kant busca "reabilitar" a aparência de seu tratamento tradicional, que consistia apenas na sua oposição à verdade, logo a interpretando como simples ilusão, "uma semelhança enganadora da percepção sensível".

Para o Kant da Crítica, a aparência não é apenas a impressão sensível arbitrária, não distinguível, portanto, da ilusão. A ilusão (Täuschung), bem entendida, consiste da aceitação da aparência 
(Erscheinung) como se esta fosse "coisa em si mesma" (Noumenon). Sobre a aparência, diz Kant: é "aquilo que não se deve procurar no objeto em si, mas sempre na relação desse objeto ao sujeito e é inseparável da representação do primeiro, é a aparência (fenômeno)" (KANT, 1994, B 70, nota). A aparência, para Kant, dito de forma sumária, não é nem a coisa ela mesma, nem uma ilusão que a partir desta produziria nossos sentidos, mas é o que percebemos na coisa em conformidade com as formas puras da sensibilidade e do entendimento.

Em Hegel, por sua vez, Erscheinung permanece distinto da ilusão, porém não mais se aceita o caráter incognoscível da coisa em si, sendo Erscheinung a aparência de uma essência da qual nada permanece oculto. Cabe-nos aqui apenas ressaltar que noções como aparência são fruto de intenso debate desde o século XVIII, debates nos quais a questão do conhecimento tem a primazia, e que Marx é tanto herdeiro como crítico desta tradição, não desconhecendo as ambivalências semânticas das palavras que escolhe em O Capital. Em Marx a implicação "epistêmica" do Erscheinung é presidida pela implicação política da crítica da sociedade burguesa. A aparência é tida sobretudo negativamente, embora esta não se confunda com a ilusão, nem mesmo com erro dos sentidos, mas antes é fruto do feitiço. Participa do corolário desta noção o aspecto luminoso do "brilho" e "fulgor" presentes no sentido alemão de Schein, entendido como brilho que mostra a coisa à qual a aparência reporta.

É certo que em Marx aparência e essência não são coincidentes, ao contrário, a exposição revelando a essência refuta seu aparecimento invertido. Como a aparência e a consciência dos agentes são coincidentes, o desenvolvimento da exposição é demonstração da parcialidade da consciência imediata dos agentes, donde toda a crítica ao feitiço da mercadoria. Não se pode deixar de assinalar, contudo, que a aparência não pode ser descartada, antes é seu desenvolvimento contraditório o caminho para a demonstração da essência. A ilusão não é dimensão da aparência, mas a confusão desta com a essência. Dito de forma sintética: essência, aparência e ilusão são dimensões distintas da coisa. 
A aparência, como a entendemos, é a epiderme da essência. A metáfora, porém, não pode ser explorada apenas pelo âmbito de sua exterioridade, como se fosse o caso de se tratar de um "epifenômeno" passageiro e extrínseco à essência. Antes deve designar seu caráter ambivalente, por um lado, de dimensão que vela o sentido profundo da contradição necessária; por outro, de camada essencial à sobrevivência da essência que esta protege. Apenas o método de exposição, entendido como crítica, pode nos revelar todas as camadas da epiderme e nos guiar por meio delas ao coração de onde pulsam as contradições do mundo capitalista e que sua epiderme oculta ao mesmo tempo em que, pela crítica, pode revelar.

O trabalho crítico consiste em não se deixar ofuscar pelo brilho do que aparece, nem tampouco reputar as aparências como simples ilusões. Antes consiste em entender as aparências como tais, investigar o nexo que une essência e aparência e, após este entendimento positivo, expor as regras da inversão de sentido que a aparência contém.

As categorias, mesmo aquelas demonstradas como aparentes, não são abandonadas antes de extrair-se delas todas as suas possibilidades analíticas. Nesse sentido é que podemos dizer que as noções presentes na Circulação simples são abstratas. São abstratas em sentido hegeliano, isto é, "seu conceito é considerado ainda anteriormente ao processo de sua determinação e sua efetivação e independente deles" (MÜLLER, 2005, p. 11). São abstratas porque o movimento de sua concentração (Zusammenfassung) ainda não se efetivou, pois "as determinações abstratas conduzem à reprodução do concreto no plano (im Weg) do pensamento" (MARX, 1996, p.9). O abstrato é, portanto, momento do concreto, estação de seu percurso de concreção.

É fundamental abandonar a noção corrente de abstração como noção ligada a tudo o que não é coisa, noção corrente não apenas no senso comum, mas igualmente uma ressonância do materialismo vulgar, que se define antes de tudo como crença metafísica na "anterioridade" da matéria sobre o pensamento e com o qual, pensamos, Marx não está comprometido. Tampouco está comprometido com a noção de que o concreto é uma "coisa" e o abstrato é sua representação 
na idéia. Concreto e abstrato, como nos esclarece O Método da Economia Política, tem sua dialética própria, sendo o segundo "momento" do primeiro. Do mesmo modo seria insuficiente dizer, sem mais, que são "aparências", especialmente no sentido que esta expressão adquire na linguagem comum.

Cabem aqui ainda algumas considerações sobre a aparência. Aparência no sentido comum, ou do materialismo vulgar que é seu correlato, conserva apenas o lado de sua inverdade, de sua provisoriedade, de sua passagem. O termo, de forte e clara conotação hegeliana, deve nos indicar igualmente o lado de sua vinculação com a verdade ou a essência; a aparência é camada/momento da Wirklichkeit. Marx não parece desprezar o uso comum. Por vezes distingue aparência de "mera aparência", conferindo a segunda o sentido corriqueiro e por extensão dando à aparência um sentido mais técnico. Não nos aventuramos aqui a discutir as traduções, mas a ausência, ainda hoje, de um léxico estabelecido no estudo da obra de Marx faz-se sentir para quem dá seus primeiros passos nestes estudos.

Em Hegel, o substantivo "aparência" verte para o português o sentido aproximado de duas palavras: Schein, com o verbo correspondente Scheinen, e a palavra Erscheinung, com o verbo erscheinen. Schein se liga, em Hegel, a Wesen (essência), porém a essência quando Schein (aparece) deixa algo ainda de encoberto, oculto. Erscheinung é também a aparência de uma essência, mas no Erscheinung a essência não conserva nada de oculto, Erscheinung, em Hegel, é um todo ${ }^{7}$. Nos estudos sobre Marx essas distinções estão longe de ser estabelecidas. Ruy Fausto sugere traduzir Erscheinung por aparência, no sentido de fenômeno, e Schein por aparecer (FAUSTO, 1983, p. 86). Aparecer sugeriria a identidade entre essência e aparência e parecer a não identidade, mas o próprio Ruy Fausto admite a parcialidade desta distinção ${ }^{8}$.

\footnotetext{
${ }^{7}$ Ver neste sentido INWOOD, 1997.

${ }^{8}$ Como exemplo da dificuldade ressaltamos que no mesmo tomo da obra Ruy Fausto traduz Schein por aparência (idem, p. 315).
}

40 Considerações sobre a Dialética do Abstrato e do Concreto... 
Em todo caso, para Marx, a aparência tem conotações hegelianas claras, mostra a parcialidade tanto da empiria simples como a parcialidade e inverdade da consciência imediata que os homens têm dos processos que eles mesmos engendram pelo seu agir social. A aparência não é abandonada em busca da empiria reveladora, mas sim desenvolvida em suas oposições e daí as contradições que revelam sua essência. A “crítica dos modos do aparecer" não é, portanto, uma crítica que abandone a aparência, mas que a leva a sério como e enquanto aparência da essência, a ser desvelada pela crítica. As aparências, tanto quanto as abstrações, devem ser tomadas a sério e "resolvidas" em sua dialética própria e apenas esta dialética pode mostrar sua inverdade e as regras de sua conversão ${ }^{9}$.

Não basta um recurso aos "fatos" e às "coisas"; é preciso que as "coisas" e os "fatos" venham à tona pela exposição. Em uma palavra, a mistificação do mundo das mercadorias não se desfaz apenas pelo recurso ao material, ao empírico, mas sim pelo desenvolvimento das contradições imanentes em cada uma das categorias mistificadas, bem como pelo desvelamento de suas articulações no interior da sociedade burguesa moderna. A circulação simples é a aparência do mundo capitalista, sua forma abstrata, o que não pode ser entendido no sentido de ter um grau menor de ser e de verdade, mas antes como forma de manifestação contraditória que precisa ser entendida e, por meio da exposição, negada. De nada adianta dizer que é preciso ir ao concreto, o que se faz necessário, e Marx procurou dar uma resposta a tal fato, e mostrar os caminhos que nos levam do abstrato ao concreto, do aparente ao essencial.

Para encerrar ressaltamos que não se pode superestimar a epiderme do mundo capitalista, principalmente quando a consideramos como consciência dos agentes, ou seja, a esfera do fetiche, e desprezar o processo produtivo, como nos parece muito em voga. Como nos informa Marx, o real e o concreto do mundo capitalista nos aparece apenas quando descemos ao "local oculto da produção". Assim é na esfera da

${ }^{9}$ Ruy fausto prefere o neologismo "Interversão", com o qual não estamos lingüisticamente de acordo. 
produção que se passam os momentos mais fundamentais do drama capitalista. Porém, todos aqueles que, como Marx, utilizam as "armas da crítica", certamente sabem que há muito a disputar na superfície, até que do intestino desta sociedade se geste a "crítica das armas".

\section{Referências Bibliográficas}

COLLETTI, L. Il Marxismo e Hegel. Bari: Ed. Laterza, 1969.

FAUSTO, Ruy. Marx, Lógica e Política, Tomo I,São Paulo, Editora Brasiliense, 1983

GIANNOTTI, J.A. "Notas para uma análise metodológica de 'O Capital"'. São Paulo: Revista Brasiliense; n.29, 1960.

GRESPAN, J.L. O Negativo do Capital - O Conceito de Crise na Crítica de Marx à Economia Política. São Paulo: Editora Hucitec/FAPESP, 1999.

A Dialética do Avesso, in Crítica Marxista. №14, São Paulo: Boitempo Editorial, 2002.

INWOOD, Michael. Dicionário Hegel, Rio de Janeiro: Jorge Zahar Ed., 1997.

KANT, Immanuel. Crítica da Razão Pura. Tradução de Alexandre Fradique Morujão, 3ª edição, Fundação Calouste Gulbenkian, Lisboa, 1994. 
MARX, Karl. Das Kapital: Kritik der Politischen Ökonomie. I in MEW, XXIII, Berlin: Dietz Verlag, 1962.

O Capital: Crítica da Economia Política. Tradução de Regis Barbosa e Flávio R. Kothe. Os Economistas. São Paulo:Abril Cultural, 1984.

Grundrisse der Kritik der Politischen Ökonomie. Berlin: Dietz Verlag, 1974.

Para a Crítica da Economia Política. Tradução de Edgard Malagodi; Os Pensadores. São Paulo: Abril Cultural, 1999.

O Método da Economia Política. Terceira parte: Introdução [À Crítica da Economia Política] (1857). Tradução de Fausto Castilho. Campinas: IFCH, 1996. Primeira Versão.

MÜLLER, M.L. Exposição e Método Dialético em “O Capital”. Boletim SEAF N², Belo Horizonte, 1982.

Apresentação. In Introdução à Filosofia do Direito, Campinas, IFCH-Unicamp, 2005. 
